\title{
A rare coronary artery anomaly: Origin of the right coronary artery from an aortico-left ventricular tunnel
}

\author{
Florian Gundel, MD, ${ }^{\mathrm{a}}$ Eva Hendrich, MD,${ }^{\mathrm{b}}$ Michaela Horndasch, MD, ${ }^{\mathrm{a}}$ Sohrab Fratz, MD, ${ }^{\mathrm{a}}$ \\ Hans Peter Gildein, MD, ${ }^{a}$ Sizgrun Mebus, MD, ${ }^{a}$ Andreas Eicken, MD, ${ }^{a}$ Norbert Mayr, MD, ${ }^{c}$ \\ John Hess, MD, FESC, ${ }^{a}$ and Harald Kaemmerer, MD, VD, FESC, ${ }^{a}$ Munich, Germany
}

\begin{abstract}
Aortico-left ventricular tunnel (ALVT) is a rare congenital anomaly that may be associated with the right coronary artery (RCA) arising directly from the tunnel. In 1977, an ALVT with a 32-mm-wide saccular aneurysm was diagnosed in a 7-year-old boy. Corrective surgery was performed. Intraoperatively, the aortic valve (AoV) was tricuspid and normally developed. In the left coronary sinus, 2 coronary orifices were identified, lying side by side. The origin of the RCA could not be detected.
\end{abstract}

\section{CLINICAL SUMMARY}

A 12-mm round defect was seen at the sinotubular junction of the right sinus of Valsalva. This orifice led into the aneurysmally dilated part of the tunnel from where it passed through the ventricular septum and entered the left ventricle (LV) $10 \mathrm{~mm}$ caudally to the AoV. Only the aortic orifice of the tunnel was closed by suture.

Since then, there was no regular cardiologic follow-up. At the age of 37 years, the patient was referred to the Deutsches Herzzentrum München for further cardiac evaluation because of progressive aortic regurgitation.

On echocardiography, the LV was dilated (LV end-diastolic dimension of $66 \mathrm{~mm}$ ) with reduced contractility (shortening fraction of $24 \%$ ). There was severe regurgitation of the AoV. In front of the right coronary sinus, a structure suspicious of an ALVT was seen from which a coronary artery seemed to originate. Color Doppler demonstrated diastolic flow toward the LV. The right coronary cusp prolapsed into that structure. It was assumed that there was residual patency of the ALVT.

On heart catheterization, selective injections were performed into 2 severely dilated coronary arteries originating close to each other from the left coronary sinus. From both

From the Department of Pediatric Cardiology and Congenital Heart Disease, ${ }^{\mathrm{a}}$ Institute of Radiology and Nuclear Medicine, ${ }^{\mathrm{b}}$ and Department of Cardiovascular Surgery ${ }^{\mathrm{c}}$ Deutsches Herzzentrum München, Technical University, Munich, Germany. Disclosures: None.

Received for publication Feb 24, 2008; revisions received April 30, 2008; accepted for publication July 5, 2008; available ahead of print Sept 22, 2008.

Address for reprints: Harald Kaemmerer, MD, VD, FESC, Deutsches Herzzentrum München, Lazarettstr. 36, D-80636 Munich, Germany (E-mail: Kaemmerer@ dhm.mhn.de).

J Thorac Cardiovasc Surg 2010;139:e8-9

0022-5223/\$36.00

Crown Copyright (c) 2010 by The American Association for Thoracic Surgery doi:10.1016/j.jtcvs.2008.07.014

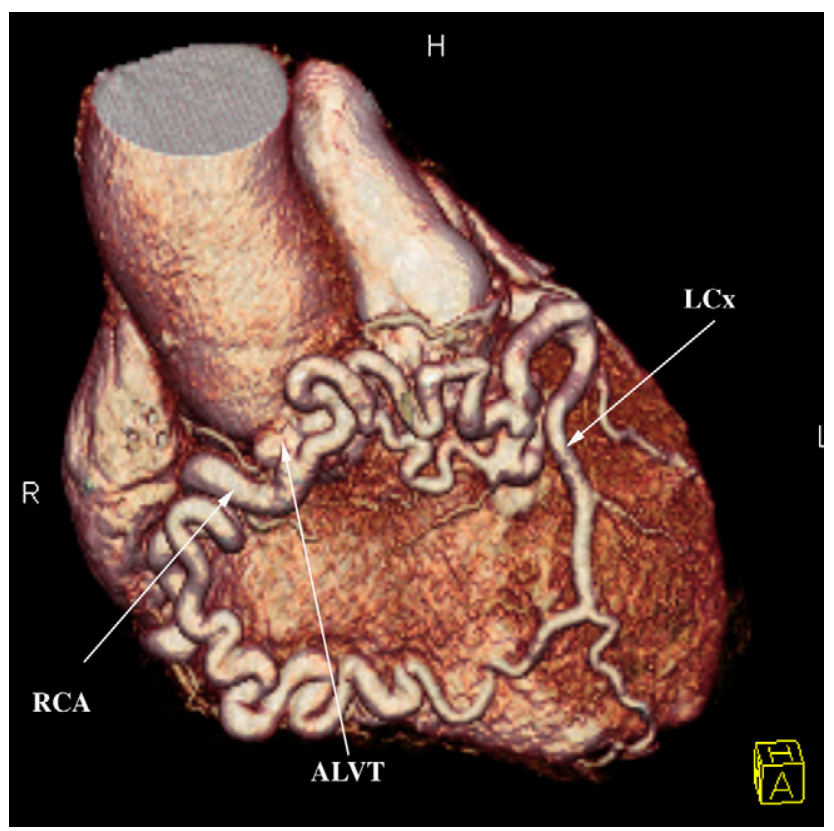

FIGURE 1. Origin of the RCA from the ALVT. Collaterals from the left coronary artery to the RCA. $L C x$, Left circumflex; $R C A$, right coronary artery; $A L V T$, aortico-left ventricular tunnel; $R$, Right; $H$, Head.

arteries, collaterals filled the dilated RCA up to its origin from where the LV outflow tract was faintly opacified. LV angiography showed flow into the ALVT billowing in systole.

Multislice computed tomography confirmed the catheter findings (Figure 1) and showed the blind aortic end of the ALVT. The ventricular end was traversing the infundibular septum just beneath the AoV. The RCA originated directly from the tunnel (Figure 2). Myocardial scintigraphy was normal.

Because of severe aortic regurgitation, an operation was indicated. On surgery, a severely dilated AoV was identified. The right coronary cusp was displaced toward the ALVT, causing central valvar incompetence. The RCA originated from the ALVT. Only selective injection into the left anterior descending artery disclosed the LV orifice of the ALVT. The AoV could not be preserved and was replaced by a biological prosthesis (Carpentier-Edwards Perimount Magna $31 \mathrm{~mm}$, Edwards Lifesciences, Irvine, Calif). On implantation of the 


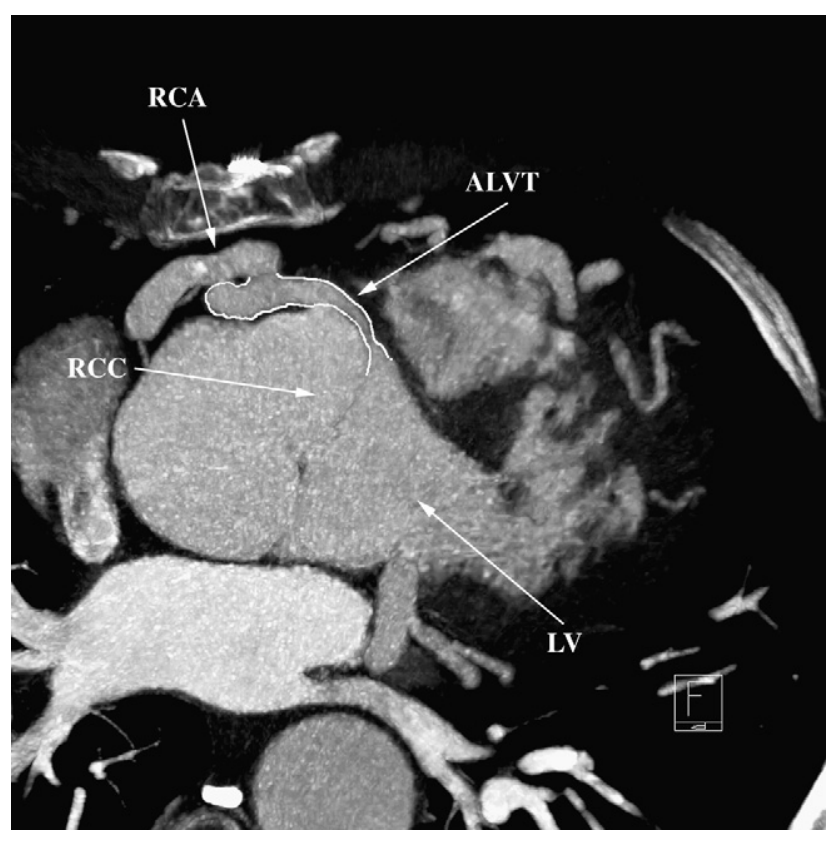

FIGURE 2. ALVT located anteriorly and laterally to the right coronary cusp with origin of the RCA. $R C A$, Right coronary artery; $R C C$, right coronary cusp; $A L V T$, aortico-left ventricular tunnel; $L V$, left ventricle.

valve, the tunnel was closed. An end-to-side anastomosis of the right internal thoracic artery to the RCA was performed.

The patient made an uneventful recovery. Myocardial scintigraphy showed no myocardial perfusion defects. Angiography demonstrated patency of the bypass and significantly less flow through the collaterals to the RCA. LV function had recovered on echocardiography (LV end-diastolic dimension of $45 \mathrm{~mm}$, shortening fraction of $30 \%$ ).

\section{DISCUSSION}

ALVT was first reported in 1963 by Levy and colleagues. ${ }^{1}$ Most patients present in early infancy, and early surgery is usually indicated because of heart failure. ${ }^{2}$ The surgical approach consists of suture or patch closure of the aortic and ventricular orifices. ${ }^{3,4}$
Our case is unique because only the aortic orifice of the tunnel was closed at the initial operation, leaving the RCA in continuity with the LV through the tunnel. Thus, there was antegrade flow in systole into the tunnel and RCA, as in healthy subjects. In diastole, however, flow reversed from the RCA into the LV, causing a coronary steal phenomenon. Collaterals from the left coronary artery to the RCA supposedly developed, and with time the coronary arteries increased in size. Initially, steal was insignificant. With progressive prolapse of the AoV into the tunnel, aortic regurgitation increased, and the patient became symptomatic. Aortic regurgitation is a major long-term concern. Despite successful surgical repair, the incidence of aortic regurgitation ranges from $16 \%$ to $60 \%$, and the requirement for AoV replacement varies from $0 \%$ to $50 \% .^{3-5}$ The potential causes for late aortic regurgitation are poorly understood and may include coexistent AoV disease, ectasia of the aortic root, and distortion of the aortic cusps at surgery. ${ }^{4}$ In the presented case, prolapse of the right coronary cusp may have led to distortion of the valve that could not be repaired, and replacement was necessary.

\section{CONCLUSIONS}

Excision of the RCA with reimplantation, as advocated by Kouchoukos and colleagues, ${ }^{2}$ was not possible for technical reasons. Because the contribution of the collaterals for perfusion of the RCA could not be defined, a bypass with the right internal thoracic artery was performed to secure coronary flow.

\section{References}

1. Levy MJ, Lillehei CW, Anderson RC, Amplatz K, Edwards JE. Aortico-left ventricular tunnel. Circulation. 1963;27:841-53.

2. Kouchoukos N, Blackstone E, Doty D, Hanley F, Karp R. Congenital Sinus of Valsalva Aneurysm and Aortico-Left Ventricular Tunnel. Cardiac Surgery. 3rd ed. Philadelphia, PA: Churchill Livingstone; 2003.

3. Horvath P, Balaji S, Skovranek S, Hucin B, de Leval MR, Stark J. Surgical treatment of aortico-left ventricular tunnel. Eur J Cardiothoracic Surg. 1991;5:113-7.

4. Martines JD, Sherwood MC, Mayer JE, Keane JF. Aortico-left ventricular tunnel 35-year experience. J Am Coll Cardiol. 2004;44:446-50.

5. Sreeram N, Franks R, Arnord R, Walsh K. Aortico-ventricular tunnel: Long-term outcome after surgical repair. J Am Coll Cardiol. 1991;17:950-5. 